Neuroepidemiology 2012;39:145-146

DOI: $\underline{10.1159 / 000341693}$

\section{Neurocysticercosis in Nonendemic Countries: Time for a Reappraisal}

\section{Oscar H. Del Brutto a, Héctor H. Garcíab, c}

${ }^{a}$ Department of Neurological Sciences, Hospital-Clínica Kennedy, Guayaquil, Ecuador; ${ }^{\mathrm{b} C e n t e r ~ f o r ~ G l o b a l ~ H e a l t h ~-~}$ Tumbes and Department of Microbiology, School of Sciences, Universidad Peruana Cayetano Heredia, and ${ }^{\mathrm{C} C y s t i c e r c o s i s ~ U n i t, ~}$ Instituto Nacional de Ciencias Neurologicas, Lima, Peru

The cystic larvae of Taenia solium frequently invade the human nervous system and cause neurocysticercosis (NCC). Infection occurs when humans ingest tapeworm eggs from a Taenia carrier through the fecal-oral route, and become intermediate hosts of this cestode. Highly endemic in Latin America, sub-Saharan Africa, the Indian Subcontinent and Southern Asia, NCC also became increasingly recognized in nonendemic countries during the past decades and is currently considered the most common helminthic infection of the nervous system and a leading cause of acquired epilepsy worldwide [1].

NCC in nonendemic countries may be locally acquired or may occur in immigrants from - or travelers to - endemic areas [2, 3]. Locally acquired NCC occurs in persons who are in close contact with an asymptomatic Taenia carrier. Human cysticercosis is mostly transmitted from person to person, and the role of infected swine is to perpetuate the infection. While swine husbandry is adequate in nonendemic countries (or nonexistent, in the case of Israel and the Arab World), T. solium carriers entering these countries may cause new autochthonous cases of NCC without the need of infected swine.

Immigrants to nonendemic countries who present with NCC are assumed to have acquired the disease in their country of origin. However, some present with 'fresh infections' (acute degenerating cysts) more than 20 years after having lived in a nonendemic country [4-6] raising the question of whether they had NCC at arrival or whether they became infected while already living in the nonendemic country. Family members usually join pioneer immigrants some years after their settlement abroad. So, recent immigration of tapeworm carriers in the settings of an immigrant community can also result in locally acquired disease in these individuals.

To acquire NCC, travelers to endemic areas must be in contact with a Taenia carrier, who will most often infect them through nonhygienic handling of food. Another possibility is that travelers get in contact with human feces by visiting rural villages, where open-air defecation is common. It is also possible that travelers first become Taenia carriers (by ingesting undercooked pork infected by cysticerci) and then infected themselves by the fecal-oral route. The most common pattern of NCC expression in travelers (single cysticercus granuloma) suggests that the most common form of disease acquisition is through contact with Taenia carriers' food handlers [3]. Otherwise, travelers would more often develop disseminated infections, as those observed in Taenia carriers who infect themselves or in those who ingest heavy loads of $T$. solium eggs directly from nature [1].

Among the traditionally considered nonendemic countries, it was in the USA where the increasing prevalence of NCC was first studied. Mass immigration of people from Latin America increased the number of NCC patients in the Southwestern USA during the eighties [7]. This was followed by the occurrence of NCC in other states, as well as by the appearance of autochthonous cases, which constitute about $5 \%$ of NCC patients diagnosed in the USA $[8,9]$. NCC should be currently considered prevalent in the USA, as more than 5,000 patients have been reported over the past years.

Recent evidence also indicates an increasing frequency of NCC in other countries that were apparently free of the disease until the past years, including Australia, Canada, Israel, Japan, Western European countries and Muslim countries of the Arab World. The current epidemiological scenario in these regions is similar to what was observed in the USA, as $70-80 \%$ of more than 1,000 NCC patients diagnosed in these countries were reported during the past two decades [3-6].

The increasing number of NCC patients in nonendemic countries is of concern. Physicians working in these regions may not be familiar with the different aspects of NCC, which in turn may cause diagnostic pitfalls (leading to the practice of unnecessary invasive procedures). Improved physician's awareness of the possibility of NCC among populations at risk (travelers, immigrants, refugees), as well as a compulsory report of cases, should allow a better assessment of the problem and identify subgroups at higher risk [10]. Also, compulsory search of Taenia carriers among household contacts of NCC patients will allow the detection of a potential source of infection, and will reduce further spread of the disease.

\section{Acknowledgements}

Dr. Garcia is supported by a Wellcome Trust International Senior Fellowship in Public Health and Tropical Medicine.

Disclosure Statement

Nothing to disclose.

\section{KARGER}

Fax +41613061234 E-Mail karger@karger.ch www.karger.com
(C) 2012 S. Karger AG, Base 0251-5350/12/0392-0145\$38.00/0

Accessible online at: www.karger.com/ned
Oscar H. Del Brutto, MD

Air Center 3542

PO Box 522970

Miami, FL 33152-2970 (USA)

Tel. +593 4228 5790, E-Mail oscardelbrutto@ hotmail.com 


\section{References}

$\checkmark 1$ Garcia HH, Del Brutto OH: Neurocysticercosis: updated concepts about an old disease. Lancet Neurol 2005;4:653-661.

$\checkmark 2$ Garcia HH: Neurocysticercosis in immigrant populations. J Travel Med 2012;19:73-75.

$\checkmark 3$ Del Brutto OH: Neurocysticercosis among international travelers to disease-endemic areas. J Travel Med 2012;19:112-117.

4 Del Brutto OH: Neurocysticercosis in Australia: still free of autochthonous cases? Med J Aust 2012;196:385.

5 Del Brutto OH: A review of cases of human cysticercosis in Canada. Can J Neurol Sci 2012;39:319-322.

6 Del Brutto OH: Neurocysticercosis in Western Europe. A re-emerging disease? Acta Neurol Belg DOI: 10.1007/S13760-012-0068-3.
7 Richards FO Jr, Schantz PM, Ruiz-Tiben E, Sorvillo FJ: Cysticercosis in Los Angeles County. JAMA 1985;254:3444-3448.

8 Wallin MT, Kurtzke JF: Neurocysticercosis in the United States. Review of an important emerging infection. Neurology 2004;63:15591564.

-9 Sorvillo F, Wilkins P, Shafir S, Eberhard M: Public health implications of cysticercosis acquired in the United States. Emerg Infect Dis 2011;17: $1-6$.

10 Roman G, Sotelo J, Del Brutto OH, Flisser A, Dumas M, Wadia N, Botero D, Cruz M, Garcia H, de Bittencourt PR, Trelles L, Arriagada C, Lorenzana P, Nash TE, Spina-França A: A proposal to declare neurocysticercosis an international reportable disease. Bull WHO 2000;78: 399-406. 